\title{
Unexpected nuclear localization of Cdc25C in bovine oocytes, early embryos, and nuclear-transferred embryos
}

\author{
Laurence Gall, Daniel Le Bourhis ${ }^{1}$, Sylvie Ruffini, Claire Boulesteix and Xavier Vignon \\ INRA, UMR 1198, ENVA, CNRS, FRE 2857, Biologie du Développement et Reproduction, 78352 Jouy en Josas \\ Cedex, France and ${ }^{1}$ UNCEIA, Department of R\&D, 13, rue Jouët, 94704 Maisons-Alfort, France
}

Correspondence should be addressed to L Gall; Email: laurence.gall@jouy.inra.fr

\begin{abstract}
It is clear from a wide range of studies that the nuclear/cytoplasmic distribution of Cdc25C has important functional consequences for cell cycle control. It is now admitted that in somatic cells, the localization of $\mathrm{Cdc} 25 \mathrm{C}$ in the cytoplasm is required to maintain the cell in an interphasic state and that $\mathrm{Cdc25C}$ has to translocate to the nucleus just before $\mathrm{M}$-phase to induce mitotic events. We characterized the expression and localization of $\mathrm{Cdc} 25 \mathrm{C}$ during oocyte maturation, the first embryo mitosis, and the first steps of somatic cell nuclear transfer (SCNT) in cattle. We demonstrated that Cdc25C was expressed throughout the maturation process and the early development. We clearly showed that $\mathrm{Cdc} 25 \mathrm{C}$ was localized in the nucleus at the germinal vesicle stage and during the early development until the blastocyst stage. However, the signal change in blastocyst and Cdc25C became cytoplasmic as is the case in somatic cells. Thus, oocytes and early embryonic cells presented a specific nuclear Cdc25C localization different from the one observed in somatic cells, suggesting that Cdc25C could have a particular localization/regulation in undifferentiated cells. Following SCNT, Cdc25C became nuclear as soon as the nucleus swelled, and this localization persisted until the blastocyst stage, as is the case in in vitro fertilized embryos. The Cdc25C nuclear localization appeared to constitute a major change, which could be associated with the reorganization of the somatic nucleus upon nuclear transfer.

Reproduction (2008) 135 431-438
\end{abstract}

\section{Introduction}

Progression through the cell cycle is mediated by cyclindependent kinases (Cdks) in complex with cyclins. The activity of cyclin/Cdk complexes is regulated at several levels: expression and proteolysis, binding of inhibitors, phosphorylation/dephosphorylation, and also subcellular localization (Nurse 1990). One of the most important steps at G2-M transition is the activation of $\mathrm{Cdc} 2 / \mathrm{cyclinB}$ (M-phase promoting factor) by the dephosphorylation of inhibitory Thr 14 and Tyr 15 residues catalyzed by cell division cycle 25C (Cdc25C), which thus plays a key role in cell cycle progression (Dunphy \& Kumagai 1991, Gautier et al. 1991, Izumi et al. 1992). Cdc25C activity, as for Cdc2/cyclinB, appears to be regulated spatially and the controlled compartmentalization of this factor is crucial to regulate the cell cycle progression. Despite the importance of Cdc25C phosphatase for the cell cycle regulation, the controlled changes of its location are not yet fully understood. Most evidence now shows that in somatic cells, during interphase, $\mathrm{Cdc} 25 \mathrm{C}$ has to be localized in the cytoplasm distant from its target Cdc2/cyclinB (Heald et al. 1993, Kumagai \& Dunphy 1999, Graves et al. 2000). The binding of Cdc25C with 14-3-3 protein is responsible for retaining Cdc25C in the cytoplasm, thereby contributing to the prevention of premature mitotic events (Heald et al. 1993, Dalal et al. 1999, Kumagai \& Dunphy 1999, Lopez-Girona et al. 1999). Just before prophase, the 14-3$3 / \mathrm{Cdc} 25 \mathrm{C}$ complex dissociates, allowing the translocation of $\mathrm{Cdc} 25 \mathrm{C}$ to the nucleus and thus the activation of $\mathrm{Cdc} 2 /$ cyclinB and the entry in M-phase (Dalal et al. 1999, Takizawa \& Morgan 2000). These findings establish that the translocation of Cdc25C into the nucleus plays an important role in governing the onset of nuclear mitotic events. This relocalization to the nucleus has been likewise described to occur just before $\mathrm{G} 2-\mathrm{M}$ transition at the meiosis resumption in Xenopus and starfish oocytes, (Izumi et al. 1992, Heald et al. 1993, Dalal et al. 1999, Kishimoto 1999, Kumagai \& Dunphy 1999, Yang et al. 1999). Surprisingly, in porcine (Dai etal. 2000) and caprine oocytes (Gall et al. 2002), a reversed situation has been observed: Cdc25C is localized in the germinal vesicle and transported to the cytoplasm at the resumption of meiosis. The biological significance and regulation of these different localizations remain unclear.

Data on Cdc25C in mammalian oocytes are available only for pig (Dai et al. 2000) and goat (Gall et al. 2002) and no data exist about Cdc25C expression and 
localization in early mammalian embryos. Bovine oocytes and embryos, which have served as an important model for many studies concerning the first steps of development and describing the nuclear remodeling that occurs after somatic cell nuclear transfer (SCNT), provide a relevant opportunity to investigate the mechanisms of specific cell cycle regulations, especially for Cdc25C. The aim of this study was to investigate Cdc25C expression and localization in bovine oocytes, early embryos, and during the SCNT procedure.

We demonstrated that Cdc25C was expressed throughout maturation and early embryonic development. We observed that Cdc25C was exclusively nuclear in oocytes at the germinal vesicle stage. Unexpectedly, $\mathrm{Cdc} 25 \mathrm{C}$ is persistently nuclear during the early development until the blastocyst stage. We observed that during the first steps of SCNT, Cdc25C became nuclear as soon as the nucleus swelled and remained nuclear during the early development.

\section{Results}

\section{Expression of Cdc25C and 14-3-3 protein in bovine oocytes and during early embryonic development}

At different times during in vitro maturation and after in vitro fertilization, oocytes and embryos were lyzed, and $\mathrm{Cdc} 25 \mathrm{C}$ and $14-3-3$ proteins were analyzed through immunoblotting using anti-Cdc25C antibody and anti14-3-3 antibody.

In bovine oocytes at the GV stage, Cdc25C was detected at $55 \mathrm{kDa}$ as a doublet that corresponds to the inactive nonphosphorylated forms of Cdc25C. After $7 \mathrm{~h}$ of culture, germinal vesicle breakdown (GVB) had occurred and the majority of the $55 \mathrm{kDa}$ form was converted to a $70 \mathrm{kDa}$ form, corresponding to the hyperphosphorylated active form of Cdc25C. At the metaphase II stage, Cdc25C was observed at $70 \mathrm{kDa}$. The amount of Cdc25C decreased between GVB and metaphase II stages (Fig. 1A). After fertilization, when oocytes were at the pronucleus stage, Cdc25C shifted down from the $70 \mathrm{kDa}$ active form to the $55 \mathrm{kDa}$ inactive form (Fig. 1B). During the early development, Cdc25C was detected mostly in a nonactive $55 \mathrm{kDa}$ form (Fig. 1B). An equivalent number of oocytes and embryos were used per lane. We observed that the amount of Cdc25C increased from the pronucleus stage to the blastocyst stage. This was probably a consequence of the increase in the number of cells. With a specific antiactive-Cdc25C that is described to recognize essentially the hyperphosphorylated active form of Cdc25C, we detected Cdc25C at $70 \mathrm{kDa}$ at the metaphase II stage as expected and as described above but also a weak labeling at $70 \mathrm{kDa}$ during development, indicating an activation of $\mathrm{Cdc} 25 \mathrm{C}$ by hyperphosphorylation during early development (Fig. 1C).
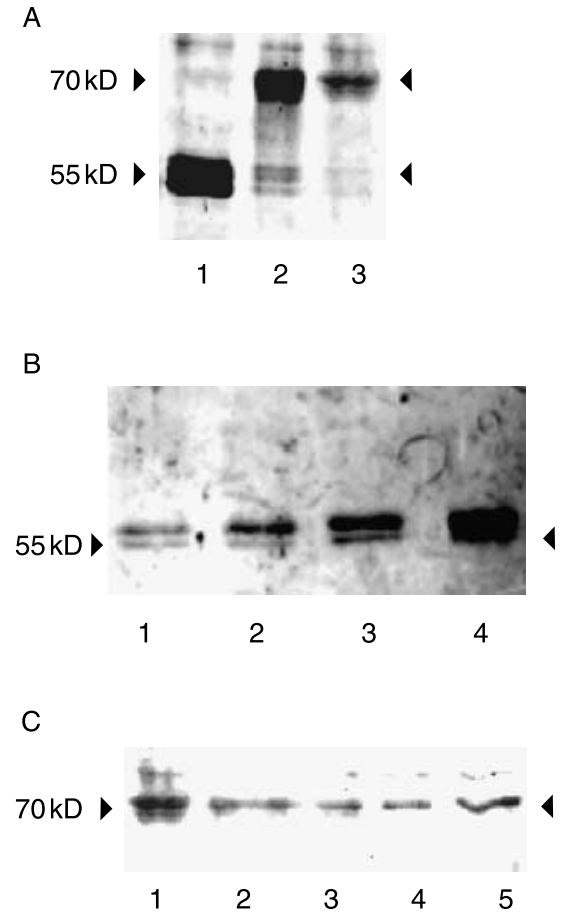

D

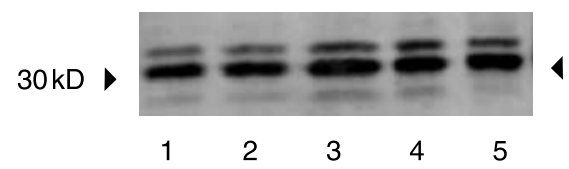

Figure $1 \mathrm{Immunodetection} \mathrm{of} \mathrm{Cdc25C} \mathrm{and} \mathrm{14-3-3} \mathrm{protein.} \mathrm{Each} \mathrm{lane}$ corresponds to 30 oocytes or embryos (A) Cdc25C during meiotic maturation. Lane 1, GV-stage oocytes; lane 2, GVB-stage oocytes; and lane 3, MII-stage oocytes. At the GV stage, Cdc25C was detected as a doublet at $55 \mathrm{kDa}$. When GVB occurred, Cdc25C shifted from 55 to $70 \mathrm{kDa}$. At the MII-stage, only the $70 \mathrm{kDa}$ form was detected. (B) Cdc25C during early development after in vitro fertilization. Lane 1, pronucleus stage; lane 2, 4-cell stage; lane 3, 8/16-cell stage; and lane 4, blastocyst stage. After fertilization, when oocytes were at the pronucleus stage, the $70 \mathrm{kDa}$ protein returned to its $55 \mathrm{kDa}$ form. During the early development, Cdc25C was detected at $55 \mathrm{kDa}$. (C) Active Cdc25C during the early development after in vitro fertilization. Lane 1, MII-stage oocytes; lane 2, 4-cell stage; lane 3, 8/16-cell stage; lane 4, morula stage; and lane 5, blastocyst stage. During the early development, phosphorylated Cdc25C at $70 \mathrm{kDa}$ was detected at a weak level. (D) 14-3-3 protein during the early development after in vitro fertilization. Lane 1, GV-stage oocytes; lane 2, MII-stage oocytes; lane 3, pronucleus stage; lane 4, 8/16-cell stage; and lane 5, blastocyst stage. During early development, 14-3-3 protein was detected at $30 \mathrm{kDa}$.

The 14-3-3 protein expression was examined in oocytes and during development and was specifically detected at $30 \mathrm{kDa}$ as expected from the GV stage to the blastocyst stage (Fig. 1D). We did not detect any modification of its expression or electrophoretic mobility during the time course of meiotic maturation and development. 


\section{Cdc25C localization during bovine oocyte maturation and early development}

The intracellular distribution of $\mathrm{Cdc} 25 \mathrm{C}$ was examined by indirect immunofluorescence using the polyclonal antibody. At the GV stage, Cdc25C was essentially localized in the germinal vesicle, and no cytoplasmic staining was observed (Fig. 2A). Nuclear staining persisted until GVB occurred. As the nuclear envelope completely dissolved, Cdc25C staining spread throughout the cytoplasm and remained distributed in the whole cell until the metaphase II stage (not shown). After in vitro fertilization, at the pronucleus stage, $\mathrm{Cdc} 25 \mathrm{C}$ was localized in the two pronuclei (Fig. 2B). From the two-cell stage to the morula stage, Cdc25C was systematically localized in the nucleus (Fig. 2C-E). When mitosis was observed in a blastomere, no specific staining around the spindle was detected. At the compact morula stage (day 6), Cdc25C is ever more nuclear (Fig. 3A and B). At day 7 of in vitro development, at the blastocyst stage, Cdc25C was no longer localized in the nucleus but was detected in the cytoplasm (Figs 2E and $3 \mathrm{C}$ and D). At the blastocyst stage, between 6 and 7 days, a modification in the $\mathrm{Cdc} 25 \mathrm{C}$ localization took place. We did not observe a difference between the cells of the inner cell mass and the trophoblastic cells concerning the localization of Cdc25C.

\section{Cdc25C localization during early development after somatic nuclear transfer}

Cdc25C intracellular distribution was examined by indirect immunofluorescence, both in the fibroblasts used for nuclear transfer and during early development after nuclear transfer (Fig. 4).

In fibroblasts, Cdc25C was essentially detected throughout the cytoplasm and was particularly abundant around the nucleus (Fig. 4A).
In our SCNT procedure, $20 \%$ of the donor nuclei underwent premature chromatin condensation (PCC) and $80 \%$ remained intact within $2 \mathrm{~h}$ after the electric pulse. Before $7 \mathrm{~h}$, regardless of the behavior of the foreign nucleus (PCC or not), Cdc25C was not evidenced in or around the nucleus transferred (Fig. 4B).

Seven hours after fusion, the embryos showed an enlarged nucleus and Cdc25C was essentially localized inside the nucleus (Fig. 4C). Twenty hours after fusion, the transferred nucleus appeared to be similar to a pronucleus and Cdc25C was nuclear (Fig. 4D). During the 2-cell, 4-cell, and 16/32-cell stages, labeling was essentially nuclear (Fig. 4E-G). At the blastocyst stage, Cdc25C was mainly localized in the cytoplasm as in in vitro-fertilized embryos (Fig. $4 \mathrm{H}$ )

\section{Discussion}

Using Western blotting and immunofluorescence analyses, we investigated the expression, phosphorylation, and localization of Cdc25C in bovine oocytes and early embryos. We showed that Cdc25C was expressed throughout the maturation process as well as during the early development. Cdc25C was detected at 55 and $70 \mathrm{kDa}$, which correspond to the nonphosphorylated inactive form and the hyperphosphorylated active form respectively, as previously described in different cell types (Millar et al. 1991, Jones \& First 1995, Dalal et al. 1999, Gall et al. 2002). At the GV stage, Cdc25C was detected at $55 \mathrm{kDa}$; during $\mathrm{G} 2-\mathrm{M}$ transition, at meiosis resumption, $\mathrm{Cdc} 25 \mathrm{C}$ became hyperphosphorylated as evidenced by a clear shift from 55 to $70 \mathrm{kDa}$. The shift from 70 to $55 \mathrm{kDa}$ was associated with a return to the interphase state after fertilization. These results are in accordance with what had previously been reported in goat and Xenopus oocytes and in somatic cells
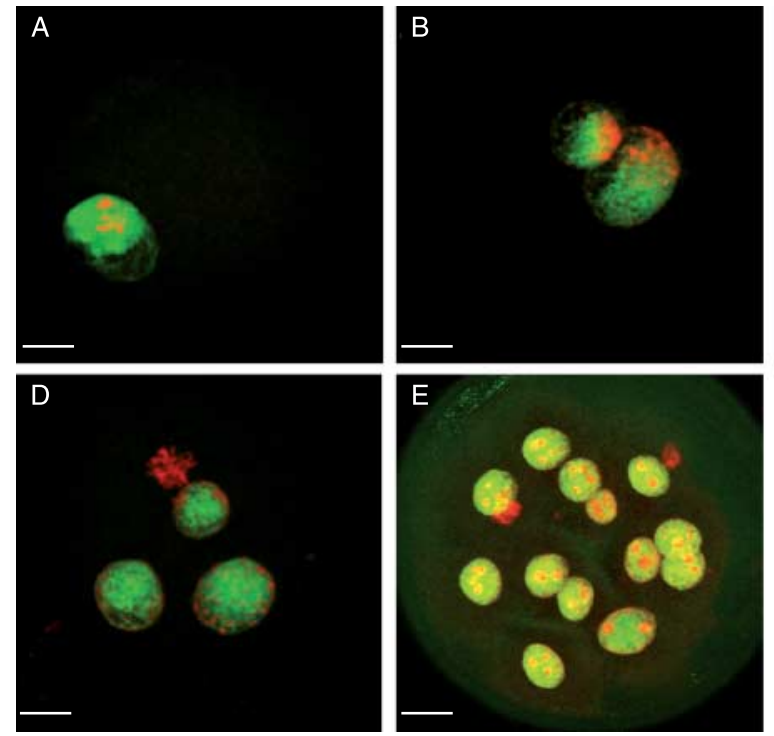
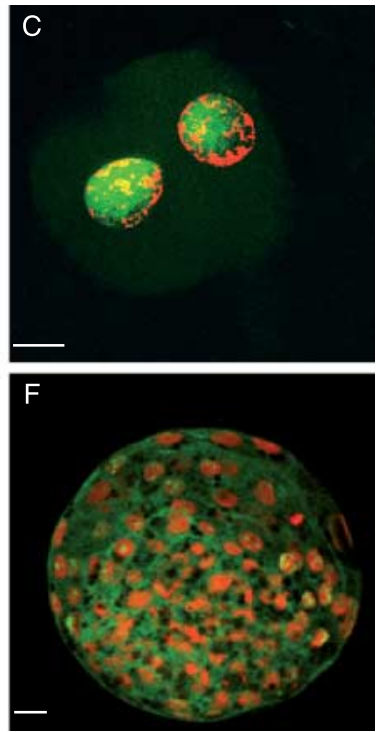

Figure 2 Immunolocalization of Cdc25C in oocytes and embryos. Each oocyte and embryo was double stained for Cdc25C (polyclonal antibody, FITC; green) and for chromatin (propidium iodide, red). (A) GV-stage oocytes; (B) pronucleus stage (18 h), (C) 2-cell stage (30 h), (D) 4-cell stage (40 h), (E) 8/16-cell stage (96 h), (F) blastocyst stage (7 days). At the GV stage, Cdc25C was localized in the germinal vesicle. At the pronuclear stage, $\mathrm{Cdc} 25 \mathrm{C}$ was localized in the two pronuclei. From the two-cell stage to the morula stage, Cdc25C was localized in the nucleus. At the blastocyst stage, Cdc25C was detected in the cytoplasm. Bars $=20 \mu \mathrm{m}$. 

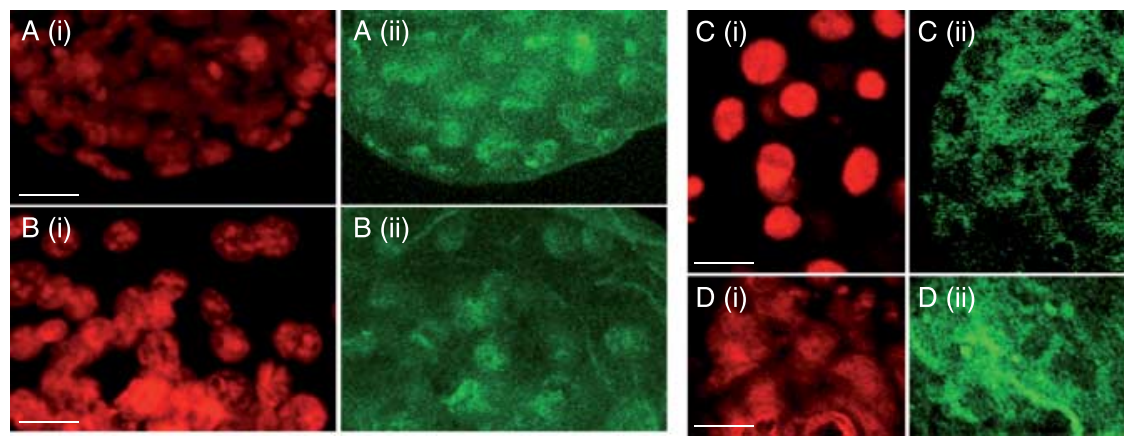

Figure 3 Immunolocalization of $\mathrm{Cdc} 25 \mathrm{C}$ in morula and blastocyst stages. Each embryo was double stained for Cdc25C (FITC: A(ii), $\mathrm{B}(\mathrm{ii}), \mathrm{C}(\mathrm{ii}), \mathrm{D}(\mathrm{ii}))$ and for chromatin (propidium iodide: $A(i)$, B(i), C(i), D(i)). (A, B) Compact morula stage ( 6 days) and (C, D) blastocyst stage ( 7 days). At the compact morula stage, Cdc25C is even clearly nuclear. The signal changed at the blastocyst stage and Cdc25C became clearly cytoplasmic. Bars $=20 \mu \mathrm{m}$.
(Kumagai \& Dunphy 1992, Hoffmann et al. 1993, Hoffmann \& Karsenti 1994, Galaktionov et al. 1995, Izumi \& Maller 1995, Karaïskou et al. 1998, PérezMongiovi et al. 2000, Gall et al. 2002), and indicated that, in bovine oocytes the $\mathrm{G} 2-\mathrm{M}$ transition during maturation process is accompanied by the $\mathrm{Cdc} 25 \mathrm{C}$ activation due to hyperphosphorylation. During the early development, Cdc25C was mostly expressed in the $55 \mathrm{kDa}$ nonphosphorylated form until the blastocyst stage and only a weak amount of active phosphorylated Cdc25C was detected. Indeed, the Cdc25C activity is undetectable during interphase and become measurable only as cells enter mitosis. During the early development, at any given time, only $10-15 \%$ of embryonic blastomeres are in M-phase, thus it is not surprising to detect only very little phosphorylated Cdc25C. Furthermore, the hyperphosphorylation of Cdc25C occurring during early prophase of mitosis is a fast transitory phenomenon not easily evidenced.

It is clear from a wide range of studies that the nuclear/cytoplasmic distribution of Cdc25C has important functional consequences for cell cycle control, but a complete understanding of its localization and spatio-temporal regulation is missing. During the G2phase, in somatic cells as well as in Xenopus laevis and starfish oocytes, Cdc25C is required in the cytoplasm and it translocates to the nucleus shortly prior to M-phase to trigger M-phase events (Izumi et al. 1992, Heald et al. 1993, Dalal et al. 1999, Kishimoto 1999, Kumagai \& Dunphy 1999, Lopez-Girona et al. 1999, Yang et al. 1999). Our results on cultured bovine fibroblasts confirmed this somatic cytoplasmic localization. But in bovine oocytes, Cdc25C was exclusively found in the nucleus at the germinal vesicle stage. This particular localization is similar to what had previously been observed in pig and goat oocytes (Dai et al. 2000, Gall et al. 2002). Cdc25C thus appears to be differently located in both the germinal and somatic cells in mammals. These results suggest that although the same set of proteins drives mitosis and meiosis, different regulatory strategy could be involved during mitosis and meiosis. Surprisingly, after in vitro fertilization in cattle, Cdc25C was localized in the two pronuclei (male and female) and during the early development, strong nuclear localization of Cdc25C in all blastomeres was detected until blastocyst stage. Preliminary experiments on mouse embryos indicated the same behavior of Cdc25C during the early development (unpublished data). All the results presented above demonstrate that Cdc25C, contrary to what is known in somatic cells, is always located in the nucleus in oocytes and embryonic cells, until the blastocyst stage, even during interphase. We could postulate that these two conditions of Cdc25C, somatic and embryonic, could undergo different regulatory strategies. In somatic cells, it has been described that during interphase, Cdc25C is found predominantly in the cytoplasm associated with 14-3-3 protein. This association is responsible for retaining $\mathrm{Cdc} 25 \mathrm{C}$ in the cytoplasm, thereby contributing to the prevention of initiation of mitotic events. At G2-M transition, the Cdc25C/14-3-3 complex dissociates, which may allow Cdc25C to accumulate in the nucleus and to promote mitosis (Nebrada \& Ferby 2000, Takizawa \& Morgan 2000, Duckworth et al. 2002). We have observed that 14-3-3 protein was expressed in bovine oocytes and during the early development, indicating that permanent nuclear Cdc25C localization was not due to an absence of 14-3-3 protein. One possibility is that $14-3-3$ protein becomes modified during oogenesis and early development, reducing its binding activity and causing its dissociation from $\mathrm{Cdc} 25 \mathrm{C}$, which results in a permanent nuclear localization. Another suggestion is that Cdc25Cbinding sites for 14-3-3 protein, regulated by phosphorylation, may be defective during the oogenesis and early development.

At the blastocyst stage, the localization of Cdc25C changed drastically and cytoplasmic localization became obvious, as was the case for somatic cells. We did not observe any differences for the localization of Cdc25C between inner cell mass and trophectodermal cells. The cytoplasmic localization of Cdc25C appears in the blastomeres at the blastocyst stage, 

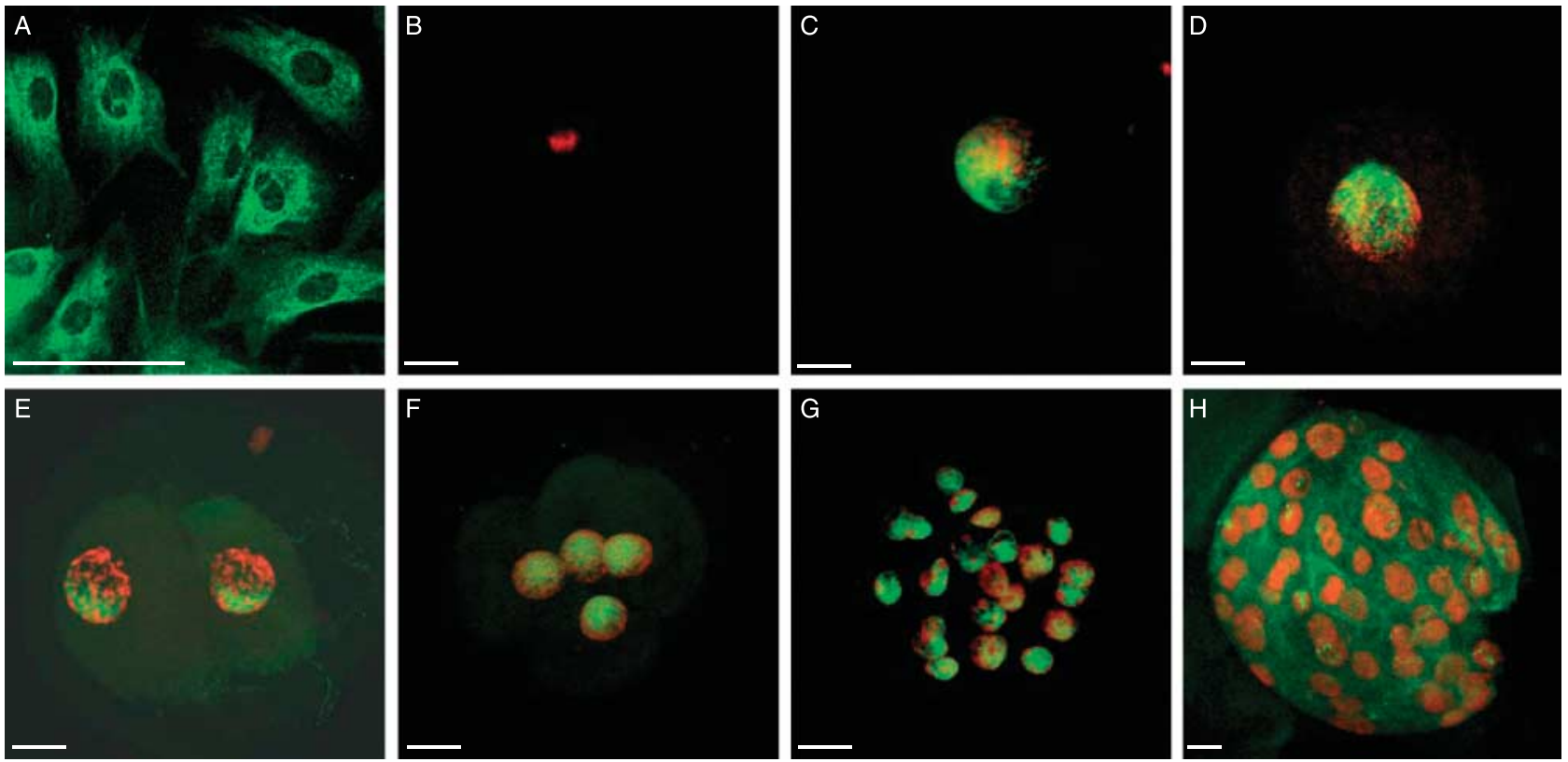

Figure 4 Immunolocalization of Cdc25C after somatic cell nuclear transfer. Each oocyte and embryo was double stained for Cdc25C (FITC, green) and for chromatin (propidium iodide, red). (A) Bovine fibroblasts; (B) $2 \mathrm{~h}$ after fusion; (C) $7 \mathrm{~h}$ after fusion; (D) $20 \mathrm{~h}$ after fusion, pronucleus stage; (E) 2-cell stage (26 h); (F) 4-cell stage (34 h); (G) 16/32-cell stage (100 h); and (H) blastocyst stage (7 days). In fibroblasts, $\mathrm{Cdc} 25 \mathrm{C}$ was essentially detected in the cytoplasm. Some patches of $\mathrm{Cdc} 25 \mathrm{C}$ were observed in the nucleus. No detectable labeling was observed in the nucleus $2 \mathrm{~h}$ after fusion. The nucleus had swelled $5 \mathrm{~h}$ post transfer and $\mathrm{Cdc} 25 \mathrm{C}$ appeared inside the nucleus. From the one-cell stage to the morula stage, Cdc25C was localized in the nucleus. At the blastocyst stage, Cdc25C was localized essentially in the cytoplasm. Bars $=20 \mu \mathrm{m}$.

at the same time as the first differentiations. Altogether, these data suggest that $\mathrm{Cdc} 25 \mathrm{C}$ could have a specific localization/regulation in undifferentiated cells when compared with the somatic differentiated ones. It was therefore interesting to observe the behavior of Cdc25C in the SCNT procedure during which a somatic nucleus is set into a germinal cytoplasm. The SCNT is performed using oocytes as the cytoplasm recipient and somatic cells as the nucleus donor. The reconstructed embryo is then artificially activated by different protocols in order to initiate the embryonic development. In successful experiments, the donor nucleus is supposed to be reprogrammed so that it matches embryonic characteristics compatible with a full-term development of the reconstructed embryo (review Campbell et al. 2005). The reprogramming of a donor nucleus is a complex process that involves remodeling of nuclear structures, epigenetic modifications of the chromatin, and expression of transcriptional regulators (Vignon et al. 2002, Alberio et al. 2006). It is not yet known how the somatic cell cycle regulation is modified to fit with an embryonic regulation. The premise is that if the donor nucleus is successfully reprogrammed, it first must be remodeled to a state similar to that of a pronucleus and the somatic regulation of $\mathrm{Cdc} 25 \mathrm{C}$ has to turn to an embryonic regulation. Upon nuclear transfer into an enucleated oocyte, a massive nuclear swelling accompanied by chromatin decondensation occurs. This reflects an exchange of proteins, which is an important aspect of remodeling. During our cloning procedure, $80 \%$ of transferred nuclei retained their initial state and 20\% underwent nuclear envelope breakdown, lamina disassembly, and premature chromatin condensation (PCC). Interestingly, we could generate up to $38 \%$ of development to the blastocyst stage with such a protocol (Vignon et al. 2002; present studies). This suggests that reprogramming of the somatic nucleus is not directly linked to the occurrence of PCC upon nuclear transfer; this was also demonstrated in ovine species where the frequency of development to the blastocyst stage did not differ whatever be the rate of PCC (Lee \& Cambell 2006). The somatic nucleus appeared to be deprived of Cdc25C until $7 \mathrm{~h}$ after fusion, whatever be the morphological remodeling (PCC or not). From $7 \mathrm{~h}$ post fusion, transferred nucleus (PCC or not) underwent nuclear swelling that resembled the conditions occurring at pronucleus formation after fertilization. At this stage, every foreign nucleus presented a dense Cdc25C labeling similar to that observed in embryos after in vitro fertilization. These results indicate that, whatever the behavior of the foreign nucleus (PCC or not), Cdc25C is translocated to the nucleus. The translocation to the nucleus of Cdc25C during SCNT is thus a specificity of the oocyte cytoplasm. 
We characterized here one of the main modifications that affect a foreign nucleus at its introduction into an oocyte cytoplasm through nuclear transfer. It appears from this study that such a translocation is a robust process participating in nuclear reorganization. Although the biochemical basis for this reorganization is largely unknown, Cdc25C could be one of the oocyte factors associated with the somatic chromatin reorganization.

The nuclear localization of $\mathrm{Cdc} 25 \mathrm{C}$ persisted until the blastocyst stage, at which point Cdc25C localization changed and all the blastomeres presented a cytoplasmic Cdc25C localization. The blastomeres of the embryos, resulting from nuclear transfer, presented a nuclear localization of Cdc25C similar to that observed in embryos after in vitro fertilization. The present study provides evidence that the embryonic and trophoblastic cells from the cloned embryos are similarly regulated, for Cdc25C, when compared with those from a fertilized embryo. Finally, we show that the developmentally regulated change in $\mathrm{Cdc} 25 \mathrm{C}$ localization is not related to the occurrence of PCC in the somatic nucleus after its transfer into an oocyte. This suggests that such remodeling events can take place without the complete loss of the somatic nuclear envelope.

Further studies are under investigation to evaluate more precisely the roles of Cdc25C during the early development, which might explain a particular nuclear localization and to determine whether $\mathrm{Cdc} 25 \mathrm{C}$ could be one of the oocyte factors implicated to allow the return of a differentiated nucleus to pluripotency.

\section{Materials and Methods}

\section{Oocyte collection and in vitro maturation}

Cattle ovaries were obtained from a slaughterhouse and transported to the laboratory in sterile PBS at $35^{\circ} \mathrm{C}$ within $3 \mathrm{~h}$. The detailed protocols have been described elsewhere (Heyman et al. 1994). Briefly, cumulus oocyte complexes (COCs) were aspirated in TCM 199 (Sigma) from 3 to $6 \mathrm{~mm}$ diameter follicles. Compact COCs with several dense layers of cumulus cells were selected and washed three times in TCM 199. Some oocytes (at the germinal vesicle stage) were mechanically denuded and used for western blot or immunofluorescence analysis. Maturation was performed in culture dishes (Nunclon Delta, Gibco) in TCM 199 supplemented with $10 \%$ fetal calf serum (FCS; Life Technologies), $10 \mu \mathrm{g} / \mathrm{ml}$ porcine follicle-stimulating hormone/luteinizing hormone (Stimufol, Merial, Lyon, France), and $1 \mu \mathrm{g} / \mathrm{ml}$ estradiol $17-\beta$, for $22 \mathrm{~h}$ at $39^{\circ} \mathrm{C}$ in a humidified atmosphere of $5 \% \mathrm{CO}_{2}$ in air. Under our experimental in vitro conditions, we obtained maturation rates of $90 \%$. At the end of the maturation period, in vitro matured oocytes were used for in vitro fertilization (IVF), SCNT, or analyzed using Western blot and immunofluorescence.

\section{IVF and development}

Twenty-two hours after the onset of maturation, oocytes were co-incubated with heparin-capacitated frozen-thawed spermatozoa in Tyrode's albumin lactate pyruvate medium for $18 \mathrm{~h}$ according to the standard technique routinely used in the laboratory (Revel et al. 1995). After IVF, presumptive zygotes were cultured in microdrops of $50 \mu \mathrm{l}$ B2 medium (CCD, Paris, France) with $2.5 \%$ FCS, seeded with Vero cells (Menck et al. 1997). The droplets were overlaid with mineral oil (M8410, Sigma) and incubated for 7 days at $39{ }^{\circ} \mathrm{C}$ under $5 \% \mathrm{CO}_{2}$. Cleavage was assessed at day 2 after insemination and blastocyst formation was evaluated at day 7 . Under our experimental in vitro conditions, $87 \%$ of zygotes cleaved and 58\% reached the blastocyst stage. For immunofluorescence and Western blot analyses, zygotes and embryos were analyzed at 18 h, 30 h, 40 h, 96 h, 6 days, and 7 days, which corresponded to the pronucleus, 2-cell, 4-cell, 8/16-cell, compact morula, and blastocyst stages respectively.

\section{Somatic nuclear transfer}

Somatic cloning was performed as described elsewhere (Vignon et al. 2000). Donor cells from adult skin biopsies were cultured over 4-10 passages. The fibroblasts were grown in $60 \mathrm{~mm}$ Petri dishes in order to obtain a quiescent population of cells on the day of SCNT. The cells were trypsinized, pelleted, and resuspended in fresh TCM 199. After the maturation, oocytes were denuded from cumulus cells and enucleated at $22 \mathrm{~h}$. A single fibroblastic cell was fused to enucleated metaphase II oocytes with a double electric pulse of $2.0 \mathrm{KV} / \mathrm{cm}$ for $30 \mu \mathrm{s}$. Reconstituted embryos were activated with $10 \mu \mathrm{g} / \mathrm{ml}$ cycloheximide and $5 \mu \mathrm{g} / \mathrm{ml}$ cytochalasin B for $5 \mathrm{~h}$ and then cultured in B2 medium as described above. Under these conditions, $96 \%$ of the stimulated oocytes formed pronuclei. Cleavage and blastocyst rate were 80 and $45 \%$ respectively. For the immunofluorescence analysis, reconstituted embryos were collected at $2 \mathrm{~h}, 7 \mathrm{~h}, 20 \mathrm{~h}, 26 \mathrm{~h}, 34 \mathrm{~h}$, $100 \mathrm{~h}$, and 7 days, which corresponded to the intact foreign nucleus, swollen foreign nucleus, pronucleus, 2-cell, 4-cell, 16/32-cell, and blastocyst stages respectively.

\section{Western blot analysis}

Oocytes and embryos (set of 30) were lyzed in SDS-sample buffer and polypeptides were separated using 10\% SDS-PAGE, as previously described by Laemmli (1970). Stained proteins of known molecular mass (range: 14-200 kDa, Amersham) were run simultaneously as standards. The electrophoretically separated polypeptides were transferred onto a PVDF membrane (Hybond-P PVDF; Amersham). The membrane was blocked by incubation in PBS 1/1000 Tween-20 (PBS-T; Prolabo, VWR, Fontenais-sous-Bois, France) containing $4 \%$ nonfat dry milk and incubated with the first antibodies (rabbit polyclonal antiCdc25C, diluted 1/300; Santa Cruz Biotechnology, Santa Cruz, CA, USA; mouse monoclonal anti-active-Cdc25C, diluted 1/300, Upstate Biotechnology; and rabbit polyclonal anti-14-3-3, diluted 1/1000, Santa Cruz Biotechnology) diluted in PBS-T 4\% nonfat dry milk, for $2 \mathrm{~h}$ at room temperature. The blot was then washed three times with PBS-T and incubated in PBS-T 4\% 
nonfat dry milk, containing the peroxidase-conjugated antirabbit or anti-mouse IgG antibody (1/5000; Biosys Vector Lab. Inc, Burlingame, CA, USA) and washed extensively in PBS-T. Peroxidase activity was revealed using the ECL-Plus Western blotting detection system as per the manufacturer's instructions (Amersham). Immunoreaction signals were analyzed using an image analysis system (Advanced Image Data Analyzer software, LAS 1000 camera; Fujifilm, FSVT, Courbevoie, France). Each experiment was repeated at least five times.

\section{Immunofluorescence}

Denuded oocytes, IVF embryos, and reconstituted embryos were fixed in Recta Pur methanol (Prolabo, VWR) at $-20^{\circ} \mathrm{C}$ for $10 \mathrm{~min}$. Fibroblasts were grown on glass coverslips and fixed in cold methanol as above. The samples were washed several times in PBS and then incubated for $1 \mathrm{~h}$ in PBS supplemented with $2 \%$ BSA, which were then incubated for $2 \mathrm{~h}$ with the first antibody (rabbit polyclonal anti-Cdc25C, diluted 1/300; Tebu, Santa Cruz Biotechnology) and rinsed for $1 \mathrm{~h}$ by extensive washes in PBS-BSA. The cells, oocytes, and embryos were then incubated for $1 \mathrm{~h}$ in fluorescein isothiocyanatelabeled anti-rabbit IgG (Biosys) diluted 1/500 in PBS-BSA. The samples were then exposed for a few minutes to propidium iodide $(10 \mu \mathrm{g} / \mathrm{ml}$; Invitrogen), mounted in a PBS-glycerol mixture (City University, London) and observed under confocal microscopy (Zeiss LSM 310).

\section{Acknowledgements}

We are grateful to Dr J P Renard and Dr O Sandra for their critical reading of the manuscript. We thank $C$ Poirier for his assistance with the preparation of images for the manuscript. Immunofluorescence studies were performed on confocal microscope from platform MIMA2 Jouy en Josas, http://voxel. jouy.inra.fr/mima2. The authors declare that there is no conflict of interest that would prejudice the impartiality of this scientific work.

\section{References}

Alberio R, Campbell KHS \& Johnson AD 2006 Reprogramming somatic cells into stem cells. Reproduction 132 709-720.

Campbell KHS, Alberio R, Choi I, Fisher P, Kelly RDW, Lee JH \& Maalouf W 2005 Cloning: eight years after Dolly. Reproduction in Domestic Animals 40 256-268.

Dai Y, Lee C, Hutchings A, Sun Y \& Moor R 2000 Selective requirement for Cdc25C protein synthesis during meiotic progression in porcine oocytes. Biology of Reproduction 62 519-532.

Dalal SN, Schweitzer CM, Gan J \& DeCaprio JA 1999 Cytoplasmic localization of human cdc25C during interphase requires an intact 14-33 binding site. Molecular and Cellular Biology 19 4465-4479.

Duckworth BC, Weaver JS \& Ruderman JV 2002 G2 arrest in Xenopus oocytes depends on phosphorylation of cdc25 by protein kinase A. PNAS 99 16794-16799.

Dunphy WG \& Kumagai A 1991 The cdc25 protein contains intrinsic phosphatase activity. Cell 67 189-196.

Galaktionov K, Jessus C \& Beach D 1995 Raf1 interaction with Cdc25 phosphatase ties mitogenic signal transduction to cell cycle activation. Genes and Development 9 1046-1058.
Gall L, Ruffini S, Le Bourhis D \& Boulesteix C 2002 Cdc25C expression in meiotically competent and incompetent goat oocytes. Molecular Reproduction and Development 62 4-12.

Gautier J, Solomon MJ, Booher RN, Bazan JF \& Kirschner MW 1991 Cdc25 is a specific tyrosine phosphatase that directly activate p34cdc2. Cel/ 67 197-211.

Graves PR, Schwarz JK, Gales J, Sausville EA, O'Connor PM \& PiwnicaWorms H 2000 The chk1 protein kinase and the Cdc25C regulatory pathways are targets of the anticancer agent UCN-01. Journal of Biological Chemistry 275 5600-5605.

Heald R, McLoughlin M \& McKeon F 1993 Human Wee1 maintains mitotic timing by protecting the nucleus from cytoplasmically activated Cdc2 kinase. Cell 74 473-474.

Heyman Y, Chesné P, Le Bourhis D, Peynot N \& Renard JP 1994 Developmental ability of bovine embryos after nuclear transfer based on the nuclear source in vivo versus in vitro. Theriogenology 42 695-702.

Hoffmann I \& Karsenti E 1994 The role of cdc25 in checkpoints and feedback controls in the eukaryotic cell cycle. Journal of Cell Science $\mathbf{1 8}$ 75-79.

Hoffmann I, Clarke PR, Marcote MJ, Karsenti E \& Draetta G 1993 Phosphorylation and activation of human cdc25-C by cdc2-cyclin B and its involvement in the self-amplification of MPF at mitosis. EMBO Journal 12 53-63.

Izumi T \& Maller J 1995 Elimination of cdc2 phosphorylation in the cdc25 phosphatase blocks initiation of M-phase. Molecular Biology of the Cell 4 1337-1350.

Izumi T, Walker DH \& Maller JL 1992 Periodic changes in phosphorylation of the Xenopus cdc25 phosphatase regulate its activity. Molecular Biology of the Cell 3 927-939.

Jones JM \& First NL 1995 Expression of the cell cycle control protein cdc25 in cleavage stage bovine embryos. Zygote 3 133-139.

Karaïskou A, Cayla X, Haccard O, Jessus C \& Ozon R 1998 MPF amplification in Xenopus oocyte extracts depends on a two-step activation of Cdc25 phosphatase. Experimental Cell Research $\mathbf{2 4 4}$ 491-500.

Kishimoto T 1999 Activation of MPF at meiosis reinitiation in starfish oocytes. Developmental Biology 214 1-8.

Kumagai A \& Dunphy WG 1992 Regulation of the cdc25 protein during the cell cycle in Xenopus extracts. Cell 70 39-151.

Kumagai A \& Dunphy WG 1999 Binding of 14-3-3 proteins and nuclear export control the intracellular localization of the mitotic inducer Cdc25. Genes and Development 13 1067-1072.

Laemmli UK 1970 Cleavage of structural proteins during the assembly of the head of bacteriophage T4. Nature 227 680-685.

Lee JH \& Cambell KH 2006 Effects of enucleation and caffeine on maturation-promoting factor (MPF) and mitogen-activated protein kinase (MAPK) activities in ovine oocytes used as recipient cytoplasts for nuclear transfer. Biology of Reproduction 74 691-698.

Lopez-Girona A, Furnart B, Montdesert O \& Russel P 1999 Nuclear localization of Cdc25 is regulated by DNA damage and 14-3-3 protein. Nature 397 172-175.

Menck MC, Guyader-joly C, Peynot N, LeBourhis D, Lobo RB, Renard JP \& Heyman Y 1997 Beneficial effect of vero cells for developing IVF bovine eggs in two different coculture systems. Reproduction, Nutrition, Development 37 141-150.

Millar JBA, Blevitt J, Gerace L, Sadhu K, Featherstone C \& Russel P 1991 P55cdc25 is a nuclear protein required for the initiation of mitosis in human cells. PNAS 88 10500-10504.

Nebrada AR \& Ferby I 2000 Regulation of the meiotic cell cycle in oocytes. Current Opinion in Cell Biology 12 666-675.

Nurse P 1990 Universal control mechanism regulating onset of M-Phase. Nature 344 503-508.

Pérez-Mongiovi D, Beckhelling C, Chang P, Ford CC \& Houliston E 2000 Nuclei and microtubule asters stimulate maturation/M phase promoting factor (MPF) activation in Xenopus eggs and egg cytoplasmic extracts. Journal of Cell Biology 150 963-974.

Revel F, Mermillod P, Peynot N, Renard JP \& Heyman Y 1995 Low development capacity of in vitro matured and fertilized oocytes from calves compared with that of the cows. Journal of Reproduction and Fertility 103 115-120. 
Takizawa CG \& Morgan DO 2000 Control of mitosis by changes in the subcellular location of cyclin B1-Cdk1 and Cdc25C. Current Opinion in Cell Biology 12 658-665.

Vignon X, Le Bourhis D, Adenot P, Marchal J, Lavergne Y \& Laloi E 2000 Production of bovine embryos by nuclear transfer of adult skin fibroblasts: the effect of serum starvation. Theriogenology 53245.

Vignon X, Zhou Q \& Renard JP 2002 Chromatin as a regulative architecture of the early developmental functions of mammalian embryos after fertilization or nuclear transfer. Cloning and Stem Cells 4 363-377.
Yang J, Winkler K, Yoshida M \& Kornbluth S 1999 Maintenance of G2 arrest in the Xenopus oocyte: a role for 14-3-3-mediated inhibition of Cdc25 nuclear import. EMBO Journal 18 2174-2183.

Received 19 June 2007

First decision 2 August 2007

Revised manuscript received 19 December 2007

Accepted 21 January 2008 